\title{
Competing Online: Studying Consumer Choice Drivers for Online Financial Services
}

\author{
Zafar Iqbal \\ Depaul University \\ Rohit Verma \\ University of Utah
}

Given the rapid increase in the consumer use of online services and the increase in competition between firms that compete online, firms are faced with a crucial challenge. Having invested significant resources in transitioning consumers from using offline services to using online services, they now need to understand what drives consumers to choose between competing online services. Our study seeks an exploratory answer to the above challenge. Specifically, we consider, "what role do factors that drive consumers into using online services play in assisting firms better compete in the online space?" This paper explores the above question by quantifying the value that consumers of an online financial service place on having access to in-depth product information, an affordable online service, an easy to use online service, access to offline capabilities, and available marketing promotions. The results reported in this paper are based on a web-based discrete choice experiment in which 2,209 consumers were asked to compare various online financial service offerings, differing from each other in terms of the relative availability of our critical factors. The results demonstrate that consumer preferences (relative utilities) for various factors of an online financial service are different. Our results enable practicing managers to understand the factors that drive consumer choice when faced with competing online services. We believe that these results have both managerial and research implications for design, management and operations strategy formulation for online services.

\section{Introduction}

Online sales of products via transaction-based online services have been increasing since the advent of the Internet (Jupiter Media Metrix, 2002; The Industry Standard, 2000; Business Week, 2000). For example, online services enabling the sales of software, air-travel, personal computers, computer peripherals, books, music, tickets, car-rentals, and videos are all predicted to increase substantially within the next three years (Business Week, 2003; Wall Street Journal, 2003; Forrester Research, 2003). Transaction-based online services are defined as those enabling the online sales of products with a price paid per transaction (Iqbal, Verma, and Baran, 2003). Some examples of transaction-based online services include financial services, online groceries, online auctions, and music. In each of the above examples, a consumer purchases a product or service using the online medium for search, evaluation, and 
purchase while receiving the product or service with a time-lag between ordering and product delivery. Typically, such a consumer pays not only the purchase and delivery price, but also a per-transaction price for the convenience of searching, evaluating, and purchasing via the online medium.

Concomitant with the rising use of online services, researchers from numerous disciplines have been increasingly engaged in developing theories and frameworks that enable practitioners to predict online consumer behavior and also to develop better websites to ensure ease of consumer use (Stell and Paden, 2002; Koufaris, 2002; Torkzadeh and Dhillon, 2002). A majority of the still nascent online services literature has either focused on determining why consumers would prefer the online medium to the offline one (Ramaswami, Strader, and Brett, 2001; Degeratu, Rangaswamy, and Wu, 2000) or then focused on ensuring ease of use and increased benefits for consumers using the online medium (Zeithaml, Parasuraman, and Malhotra, 2000; Lynch and Ariely, 2000).

A result of these two approaches of studying online services has been an appreciation of what drives a consumer to purchase online rather than offline and what keeps the consumer loyal to the continued use of the online medium for purchase. Many factors have been offered as facilitating the above two actions-reliability of the web-site; availability of product information; special incentives; affordability; ease of use; etc. (Vellido, Lisboa, and Meehan, 2000; Zeithaml, Parasuraman, and Malhotra, 2000). In addition, the key advantages of using online services versus corresponding offline services are lower costs (Iqbal, Verma, and Baran, 2003), providing access to more detailed and timely product information (Lynch and Ariely, 2000), and increased ease of use for customers (Zeithaml, Parasuraman, and Malhotra, 2000). To further narrow the gap between the quality of online services and that of offline services, firms are beginning to offer hybrid services that combine the best of online and offline features (Iqbal, Verma, and Baran, 2004). A comprehensive quantitative analysis of online consumer responses, using factor analysis and neural network analysis to analyze characteristics of the online medium, revealed that the factors that explained a large portion of consumers' choices to purchase online included affordability, ease-of-use, and responsiveness (Vellido, Lisboa, and Meehan, 2000). Independently, Zeithaml et al. (2000), in a comprehensive qualitative study of online consumers, revealed that factors such as ease-of-use, transaction cost, and availability of product information, among others, drove consumers' loyalty to the online medium.

The above research has been invaluable in helping practitioners and researchers understand consumer behavior in an online medium. However, given the fact that our knowledge of why consumers choose the online medium and what keeps them there is increasing, it stands to reason that we need to push the knowledge boundaries further to try and understand the role of some of the above stated factors in explaining why online consumers choose one particular online service versus another competing online service. In other words, how do consumers, choosing between competing online service offerings, allocate weights among the different features of an online service? In an analogical offline environment, 
this situation can be compared to already knowing why a consumer chooses to shop in a retail environment, but now wanting to know if that reasoning can be extended to predict at which specific retail store a consumer shops. Answering the above question will help researchers and academics design online services that increase loyalty to a particular firm's online service in addition to the online medium in general.

Thus, our current research objective is fairly straightforward. We seek to explore the relative impact of factors included in an online service in determining specific online service choice. The factors that we include in our study are those commonly cited as the significant benefits of using online services: availability of product information, ease of use of the online service, cost of using the online service, and the role of incentives in creating loyal online service users. In addition, because hybrid "click-and-mortar" online services are rapidly being developed, we also include the degree of offline capability as one of our factors. Because our research is exploratory in nature, we do not develop specific hypotheses. Our goal is primarily to understand tradeoffs between the above factors from the consumer point-of-view so that both academics and practitioners can focus on studying and designing online services that leverage features that are important to customers. However, despite being exploratory, we use a rigorous methodology, discrete choice analysis (DCA), to understand which factors most impact online service choice. Our objective is thus purely empirical-we use existing online service frameworks and seek to measure the relative impact of various factors highlighted by previous online service research as they affect choice. However, our study represents a significant departure from previous research in that our goal is to enable firms to develop customer-focused online services that are better than competing online services within a single industry, viz online financial services. Thus, our results have practical value in that they enable practicing managers to compete better by understanding the critical levers of online customer choice. Our study also furthers the knowledge boundaries within academic research by focusing on how firms should compete against each other after they have developed competing online services.

The rest of the paper is organized as follows. First, we elaborate on the factors driving online consumer behavior. Second, we describe our research methodology and sample. Third, we state the results of our study. Finally, we offer our discussion of the results and their impact on future research endeavors.

\section{Factors Driving Online Consumer Behaviors}

Among the many reasons offered for consumers to use online services in lieu of offline services, the most prominent are the depth of and breadth of product information available online (Sinha, 2000; Lynch and Ariely, 2000), the lower prices available online (Iqbal, Verma, and Baran, 2003), the ease of use of the online medium (Zeithaml, Parasuraman, and Malhotra, 2000), the hybrid nature of online services (Iqbal, Verma, and Baran, 2003), and the incentives offered by firms to transition customer to the online medium (cf. schwab.com, amazon.com). These reasons have emerged as the key drivers of online consumer behavior and consequently 
firms have invested significant amounts of resources in ensuring that their online services are designed with the above factors in mind. We consider each in turn next.

Because the online medium is predominantly information-driven, it stands to reason that firms are able to provide unprecedented amounts of product-specific information to customers (Shapiro and Varian, 1999). Product-specific information can include information about product availability, information providing access to new products, and access to indepth product research enabling better decisions (Lynch and Ariely, 2000). Customers are hence better informed about their decisions because they can access product comparisons and reviews about competing brands (Evans and Wurster, 1999). Researchers have linked the availability of more product information to reduced post-purchase dissonance and increased customer satisfaction (Zeithaml, Parasuraman, and Malhotra, 2000). Furthermore, some researchers even suggest that the availability of in-depth product information can reduce price sensitivity (Lynch and Ariely, 2000; Degeratu, Rangaswamy, and Wu, 2000). It is no surprise then that firms now offer vast amounts of product specific information including product availability, research, and review. In fact, researchers also suggest that the next generation of online competition will involve the accuracy, lack of bias, and level of detail of product information (Evans and Wurster, 1999).

However, some researchers believe that increased transparency in product information will actually increase customer price sensitivity (Sinha, 2000; Iqbal, Verma, and Baran, 2003). They attribute increased price sensitivity to the fact that besides product information, pricing information too will be increasingly available via the online medium. In a recent study, lqbal et al. (2003) demonstrated that online customers are more price sensitive than offline customers and one of the reasons cited was the increased availability of pricing information. Another reason cited for increased customer price sensitivity is the lower costs of business in the online medium. Shapiro and Varian (1999) argue that on the margin, customer acquisition and service costs are generally much lower in the online medium versus those in the offline medium. Lower marginal costs result due to the customers' using the online service to efficiently search for product information without costly human intervention (Shapiro and Varian, 1999) and also due to the ease of online service scalability (Bitner, Brown, and Meuter, 2000). As a result, lower prices are a key driver of online customer behavior.

Another factor that drives online customer behavior is the ease of use of the online service (Vellido, Lisboa, and Meehan, 2000). Ease of use refers to the convenience and control associated with using the online service (Zeithaml, Parasuraman, and Malhotra, 2000). Creating online services that are easy to use is considered to be one of the primary hurdles for service providers to cross in order to enable offline customers to transition to an online environment (Iqbal, Verma, and Baran, 2003). Offline customers, particularly those with low levels of technology knowledge, are loathe to transition to a pure online environment where they are unsure about navigating in an unfamiliar environment (Ramaswami, Strader, and Brett, 2001). Hence, firms have spent a tremendous amount of effort in ensuring that online services are 
easy to use, especially when compared to offline services. These efforts have taken a myriad of forms involving offering the ability to apply and start using the online service immediately like schwab.com, offering product configuration and decision assistance like dell.com, and real-time account updates like fidelity.com.

While online services offer multiple benefits to customers, they still face resistance for adoption unless they are able to offer a certain degree of offline capability (Iqbal, Verma, and Baran, 2003). In other words, customers still want their online services to be anchored in an offline base rather than be purely online. Even traditionally pure online companies like amazon.com have had to create a strong offline presence via warehouses and logistics centers to satisfy and reassure their customers. This form of an online service termed as "click-andmortar" is increasingly becoming the preferred form of an online service. Hence a certain degree of offline capability also seems to be driving customers' decisions to purchase online (Iqbal, Verma, and Baran, 2003). While this need dissipates with increasing online service familiarity (Iqbal, Verma, and Baran, 2003), given the fact that many customers have still to transition to an online service format, it stands to reason that possessing a certain degree of offline capability is still required to compete effectively in an online space.

Finally, firms have offered numerous incentives to transition offline customers to the online medium (cf. schwab.com, bancone.com). These incentives, typically marketing promotions, are necessary to help overcome customer inertia towards adopting online services (Verma, Iqbal, and Plaschka, 2004). Besides offering the above four factors, many times customers need additional financial incentives to transition to the online medium. These incentives work towards offsetting risks of the online medium and in many cases subsidize the transition costs incurred by customers in losing offline capabilities to gain uncertain online service benefits.

While the above five factors have been helpful in understanding why customers transition to using an online medium from an offline one, firms still need to understand how consumers tradeoff between the above five factors when choosing between two competing online services. Given the current state of academic knowledge about competing in an online environment, we turn next to highlighting the need for extending the knowledge boundaries in the online services area.

\section{Where to Next in Online Services?}

A majority of the still nascent literature in online services has focused on either transitioning customers from an offline environment to an online one or then focused on understanding online customer behavior as it differs from offline customer behavior. As a result, firms know that in order to transition customers to an online environment, they have to provide online services that offer detailed product information, lower prices, ease of using the online service, a certain degree of offline capability, and some marketing incentives. While the 
existing literature on online services is very helpful for firms, a recently emerging trend in online services reveals the need for more research.

Many firms have now created fully functional online service offerings. Online spending by customers during the holiday season in the United States grew from $\$ 8.1$ billion in 2000 to $\$ 20.4$ billion in 2003, a 150\% increase (Clickzstats.com, 2003). After the dotcom crash of 2001, many firms have replaced pure online service offerings with a combination of offline-online services (Iqbal, Verma, and Baran, 2003). As a result, firms offering online services are finding increased competition to capture customer spending. For example, in the financial services industry, firms are discovering that it is not enough to just transition offline customers into using online services. Having created online customers, brokerage firms now have to find ways to keep customers loyal to their particular brand of online service, rather than lose the customers to other competing online services (Forman, 2002). The increase in competition suggests that firms have to find a way to enhance the attractiveness of their online services relative to competition. Correspondingly, academic research also has to shift focus and provide answers to firms seeking to enhance the value of their online offerings relative to competition.

Furthermore, the previously discussed factors that influence online consumer behavior, viz. depth of product information, price per transaction, ease of use of the online service, degree of offline capability, and incentives have become part of the lexicon of firms trying to transition offline customers into using online services. Thus, firms are spending significant resources in creating online services that are competitive on the above five factors. However, now that the emphasis of competition for firms is gradually changing, firms need to understand the relative impact of the above five factors in helping customers choose between two competing online services. In other words, what relative weights do customers assign to the above five factors when choosing between two competing online services? We turn to examining this question in the next section.

\section{Research Methodology}

\section{Context}

In order to achieve our objective, we needed a research context that satisfied the following criteria. First, because we were interested in studying online consumers, our research context must allow for purchasing via the online medium. Second, we needed a context wherein existing firms were facing increased competition for online consumers. Third, we needed a context where the previously discussed five factors were existent. Finally, practical considerations required that our context allow for data collection using real consumers and appropriate sampling procedures. Therefore we chose to collect data from the online financial services industry. The online financial services industry met the above four criteria for selection in that it has an established history of providing online services, is facing increased competition evidenced by consolidation and price battles, is considerate of the five factors in our study (Ramaswami, Strader, and Brett, 2001), and has available sampling frames for data collection 
(Verma, Iqbal, and Plaschka, 2004). In the online financial services industry, we focus specifically on online brokerage services; cf. fidelity.com, schwab.com, e-trade.com, etc.

\section{Analysis Approach}

An effective and appropriate method for determining the relative value of various attributes of a new service involves modeling consumer preferences in response to experimentally designed service profiles. This approach, known as probabilistic discrete choice analysis (DCA) has been used to model choice processes of decision-makers in a variety of academic disciplines, including marketing, operations management, transportation, urban planning, hospitality, and natural resource economics (e.g., Louviere \& Timmermans, 1990; Verma, Thompson, and Louviere, 1999; Verma, Thompson, Moore, and Louviere, 2001).

Statistical models (e.g., multinomial logit models) developed from a DCA study link service attributes to consumer preferences. By describing a service in terms of appropriate attributes, DCA can be used to predict market share and profit for any service offering in a competitive environment (Danaher, 1997). Recent papers byVerma, Thompson, and Louviere (1999) and Verma, Plaschka and Louviere (2002) review DCA literature and provide guidelines for designing and conducting DCA studies for services. Hence, we only briefly describe the DCA method.

Discrete choice experiments involve careful design of service profiles (a specific service) and choice sets (a number of services) in which two or more service alternatives are offered to decision-makers and they are asked to evaluate the options and choose one (or none). Each subject in a DCA experiment typically receives several choice sets to evaluate (e.g., 8 to 32 sets) with two or more hypothetical services to choose from in each set. The design of the experiment is under the control of the researcher, and consequently, the decision-makers' choices (dependent variable) are a function of the attributes of each alternative, personal characteristics of the respondents, and unobserved effects captured by the random component (e.g., unobserved heterogeneity or omitted factors). For a detailed theoretical and statistical background of DCA please refer to Ben-Akiva and Lerman (1991) and McFadden (1986).

DCA applications based on choice experiments typically involve the following steps: (1) identification of attributes, (2) specification of attribute levels, (3) experimental design, (4) presentation of alternatives to respondents, and (5) estimation of the choice model. Although design of choice experiments and estimation of MNL models requires sophisticated training and skills, implementing the estimated model(s) in spreadsheet-based decision support systems is fairly easy. Hence, DCA is very useful for practicing managers and is used here to explore the consumer preferences for online services.

\section{Online Financial Service Attributes}

Given our conceptual variables of interest, viz. depth of product information, affordability of using the online service, ease-of-use of the online service, degree of offline 
capability of the offline service, and available marketing incentives for using the online service, we chose our financial service attributes based on their judged fit with our conceptual variables. Specifically, we collected qualitative data from four high level executives in our chosen industry and requested them to suggest online service attributes and levels that reflected our conceptual variables. Based on the executives' suggestions, and a review of existing online and offline services in our chosen industry, we modified attributes and levels to reflect the dominant customer choice-drivers. We then showed the new list of attributes to two different executives and also to the initial four executives and based on their classification we refined our list of attributes and levels. Finally, we showed our list of attributes to two business school professors, both of whom were blind to the purpose of the study and asked them to verify our classification. The inter-rater reliability was very close to $100 \%$ and subsequent discussions resolved any differences.

Table 1 lists our selected attributes, their levels, and their classification into our

\begin{tabular}{|c|c|c|}
\hline Constructs & Attributes & Levels \\
\hline \multirow[t]{3}{*}{$\begin{array}{l}\text { Depth of Product } \\
\text { Information }\end{array}$} & $\begin{array}{l}\text { Real Time Information } \\
\text { Availability }\end{array}$ & $\begin{array}{l}\text { Level 1: Yes } \\
\text { Level 2: No }\end{array}$ \\
\hline & $\begin{array}{l}\text { Access to New Product } \\
\text { Offerings }\end{array}$ & $\begin{array}{l}\text { Level 1: Yes } \\
\text { Level 2: No }\end{array}$ \\
\hline & $\begin{array}{l}\text { In-depth Research and } \\
\text { Analysis }\end{array}$ & $\begin{array}{l}\text { Level 1: Yes } \\
\text { Le Level 2: No }\end{array}$ \\
\hline Affordability & Price/transaction & $\begin{array}{l}\text { Level 1: Low } \\
\text { Level 2: Medium } \\
\text { Level 3: Medium High } \\
\text { Level 4: High }\end{array}$ \\
\hline \multirow[t]{3}{*}{ Ease of Use } & $\begin{array}{l}\text { Real Time Account } \\
\text { Status }\end{array}$ & $\begin{array}{l}\text { Level 1: Yes } \\
\text { Level 2: No }\end{array}$ \\
\hline & $\begin{array}{l}\text { Apply and Trade } \\
\text { Instantaneously }\end{array}$ & $\begin{array}{l}\text { Level 1: Yes } \\
\text { Level 2: No }\end{array}$ \\
\hline & Decision Support Tools & $\begin{array}{l}\text { Level 1: Yes } \\
\text { Level 2: No }\end{array}$ \\
\hline \multirow{2}{*}{$\begin{array}{l}\text { Degree of } \\
\text { Offline } \\
\text { Capability }\end{array}$} & $\begin{array}{l}\text { Professionally Managed } \\
\text { Accounts }\end{array}$ & $\begin{array}{l}\text { Level 1: Yes } \\
\text { Level 2: No }\end{array}$ \\
\hline & $\begin{array}{l}\text { Access to Local } \\
\text { Branches }\end{array}$ & $\begin{array}{l}\text { Level 1: Yes } \\
\text { Level 2: No }\end{array}$ \\
\hline $\begin{array}{l}\text { Marketing } \\
\text { Incentives }\end{array}$ & $\begin{array}{l}\text { Special Offer for New } \\
\text { Customers }\end{array}$ & $\begin{array}{l}\text { Level 1: } 25 \text { Free Transactions } \\
\text { Level 2: } \$ 100 \text { Credit }\end{array}$ \\
\hline
\end{tabular}

Table 1: List of Constructs, Attributes and Levels

conceptual variables of interest. In all, we manipulated eleven online service attributes at two 
levels each. Our dependent variable was the choice of the online service. The independent variables (attributes) can be classified in the following broad categories that reflect our factors of interest: depth of product information, affordability, ease of using the online service, degree of offline capability, and marketing incentives. Depth of product information was operationalized by including three attributes: (1) access to in depth research and analysis on financial products, (2) availability of real-time, in-depth financial product information, and (3) access to unique new financial products earlier than on the open market. Affordability was operationalized by varying price per transaction at four realistic levels: low $(\$ 9.95)$, medium (\$14.95), medium-high (\$19.95), and high (\$24.95). For design reasons, we created two price variables (PRICE 1 and PRICE 2), within each of which we varied price per transaction at two levels. Ease of using the online services manipulated by including three attributes: (1) availability of real-time and up-to-date account status, (2) the ability to apply for an account online and begin transacting instantaneously, and (3) the availability of advanced decision support tools that enabled easy decision making. Degree of offline capability was manipulated by including two attributes, (1) the option of account management by professional staff for an additional fee, and (2) availability of access to local brick and mortar offices. Finally, marketing incentives were manipulated by including one attribute, viz. availability of special promotions to make the usage less economically effortful, varied as either a certain number of free transactions or a comparable dollar balance to open an account. Each of the above attributes, except price per transaction and special promotions, was varied in a binary format, i.e., either as being available or not.

\section{Experimental Design}

We created 16 orthogonal fractional factorial profiles that allowed us to reliably estimate all the main effects of the attributes included (Verma, Thompson, \& Louviere, 1999). To enhance the realism of the task, a full-profile approach was used in presenting the choice sets (Green \& Srinivasan, 1990), i.e., each profile shown to the respondents simultaneously described some combination of all the attributes. In order to generate the discrete choice sets, we used a "foldover" design (Louviere, 1988). A foldover design contains the opposite levels of every attribute for a given profile and therefore presents two completely orthogonal profiles to respondents in each choice set.

We pre-tested the choice task with 50 randomly-selected consumers to ensure ease and comprehension of the task, as well as to ensure reliable data collection methods. Average task completion time was 10 minutes and respondents did not indicate difficulty in comprehension.

In addition to the online service choice task, we also asked the consumers to rate their individual involvement in the purchasing decision on a 6-point scale. The purpose of including this question was to only select the respondents with a high degree of involvement with the online service. Only those respondents that indicated a high degree of involvement with the purchase decision, i.e., answered 4 or higher on a 6-point scale, were included in our analysis. By including only involved consumers in our study, we simulated a reasonable decision made by 
firms to target involved and motivated consumers for their online service. The next section describes the sampling framework and the data collection methodology.

\section{Sampling and Data Collection}

The respondents were active consumers in the online financial services industry and were part of a demographically-balanced panel purchased from a large US-based, nationallyreputed marketing research firm. Consumer panels are an appropriate sampling frame and have a rich history of business applications (e.g., Lohse, Bellman, \& Johnson, 2000). Also, given the existing choice of sampling frames in studying online behavior, our decision to use a purchased consumer panel is consistent with the current state-of-the-art in the field (Degeratu, Rangaswamy, and Wu, 2000; Iqbal, Verma, and Baran, 2003).

The purchased panel had 10,000 consumers and the study was administered to all of them. In other words, we did not randomly sample from our chosen sampling frame but made the experiment available to all the panel consumers. Of the 10,000 consumers, only a negligible percentage (less than $2 \%$ ) chose not to respond. Thus, gross non-response bias is not a factor in our study. As discussed earlier, we screened respondents based on their response to a purchase involvement question. After screening for a high level of involvement, our sample size was 2,209 , leading to a qualified response rate of approximately $22 \%$.

The final sample contained around $29 \%$ respondents between $18-34$ years, $53 \%$ within 35-54 years and the remaining were 55 years or older. There were $66 \%$ male and $57 \%$ married respondents. Around $41 \%$ of the respondents either had a high school degree or at least some college, and $41 \%$ respondents had a post-graduate degree.

During the data collection phase, each respondent received an email from the research team with an invitation to join the research project. In addition to reimbursement from the marketing research firm for panel participation, each respondent's name was entered in a raffle for winning attractive prizes. After logging into a secure web-site, each respondent then read a common core concept of the online financial service that held constant various nonexperimental features across all choice sets. The features that were held constant included web-site reliability, on-site support, privacy, security, breadth of product assortment, and quality of information. These have been deemed as important online service features, but were held constant because they were not central to our study. After reading the core concept, each respondent was asked to respond to 16 experimentally generated online financial service choice sets. Each choice set contained two versions of the online service. A sample choice set is shown in Table 2. The respondents were asked to choose one of the two presented online service concepts, or indicate that they refused to choose either. Half the respondents made choices in one order that was then reversed for the other half of the respondents. The order made no statistical difference to the results and will not be discussed further. Similar to the pretest, average task completion time was approximately 10 minutes. 


\section{Analysis and Results}

The choice data were analyzed using maximum likelihood estimation and by developing a multinomial logit (MNL) model for the entire sample (Louviere \& Woodworth, 1983; Verma, Thompson, and Louviere, 1999). In the interest of space, we do not provide the estimation details here. These are available from the authors. The interested reader is referred to Louviere, Hensher, and Swait (2001) for methods of estimating MNL models from DCA.

\begin{tabular}{|l|l|l|}
\hline Attribute & Option \#1 & Option \#2 \\
\hline $\begin{array}{l}\text { Price/transaction } \\
\text { (presented in actual \$ amount to respondents) }\end{array}$ & High & Medium \\
\hline $\begin{array}{l}\text { Availability of in-depth research \& analysis at no } \\
\text { additional cost }\end{array}$ & No & Yes \\
\hline $\begin{array}{l}\text { Option of account management by a professional } \\
\text { staff for additional fee }\end{array}$ & Yes & No \\
\hline $\begin{array}{l}\text { Access to unique new products earlier than the open } \\
\text { market }\end{array}$ & Yes & No \\
\hline $\begin{array}{l}\text { Availability of real-time product information anytime, } \\
\text { anywhere }\end{array}$ & No & Yes \\
\hline Availability of real-time customized account status & No & Yes \\
\hline $\begin{array}{l}\text { Access to advanced analysis tools for better } \\
\text { decision-making }\end{array}$ & No & Yes \\
\hline Access to local branches & Yes & No \\
\hline $\begin{array}{l}\text { Ability to apply and start using the account online } \\
\text { within minutes }\end{array}$ & No & Yes \\
\hline Special Offer for New Customers & \$100 credit & 25 Free \\
\hline
\end{tabular}

\begin{tabular}{|l|l|l|l|}
\hline$I$ choose to use this financial service $\rightarrow$ & & Neither ___ \\
\hline
\end{tabular}

Table 2. A Sample Choice Set

The Estimated MNL Model

The estimated online financial services choice model for all respondents is summarized in Table 3. It shows b parameters (part-worth utilities) for each attribute included in the experimental design along with the intercept. A positive 2 value for an attribute means that the probability of selection of an online financial brokerage service will increase if this particular attribute in changed from being unavailable to being available. As suggested by Louviere, Hensher, and Swait (2001), we have calculated the relative utilities of both levels of each online brokerage feature and for all four levels of price. For each attribute, the relative utility for the lowest level is simply $-1 * \beta$-value. Hence, the beta-weights for all attributes that were 
manipulated at two levels are different only in sign, with the negative value representing that the attribute was not available. Since price is represented by four levels, the relative utility of the fourth level of price will be the negative of the sum of the other three $\beta$-values for price levels. The relative utilities presented in Table 3 clearly show that the probability of choice of an online brokerage service increases when the availability of attributes is changed from "no" to "yes" or if price is reduced. The table also shows McFadden $2 ?^{2}$ and Adjusted $p^{2}$ (similar to

\section{? in}

ordinary least square regression) which are aggregate measures of statistical fit of the MNL model. In addition to the overall model being significant, all estimated $b$ parameters are also statistically significant at the $5 \%$ level. For ease of explication, we have also calculated the main effects of each feature (Louviere, Hensher, and Swait, 2001). Main effects are calculated as the range of beta-weights for each attribute, i.e., the highest beta-weight value for the attribute minus the lowest beta-weight value for the attribute. Such arithmetical transformations are recommended when using DCA and enable managers to interpret and use the results more realistically (Simmons and Esser, 2000). The main effects are also provided in Table 3.

DCA also permits us to calculate the relative importance of each attribute (Simmons and Esser, 2000). This is calculated by dividing each attribute's main effect by the sum of all attribute main effects. These importance values are shown in the last column of Table 3. Furthermore, by summing up the respective attribute importance values within each of our five factors, we can calculate the importance of each factor in driving online financial service choice. This is shown in Figure 1.

\section{Relative Importance of Attributes and Factors}

As the results in Table 3 indicate, all the attributes included in the study were found to be statistically significant at $p<0.05$. Our results demonstrate that depth of product information, online service affordability, ease of use of the online service, degree of offline capability, and marketing incentives all determine whether customers choose one online service over another competing one. Thus, the factors that are instrumental in driving customers online also drive online service competitiveness.

At the individual attribute level, our results indicate the presence of six tiers of attribute preference. We calculated $95 \%$ confidence intervals for all attribute beta-weights and significant differences in beta-weights are indicated by non-overlapping confidence intervals (Louviere, Hensher, and Swait, 2001). We find that for an online financial service, low price per

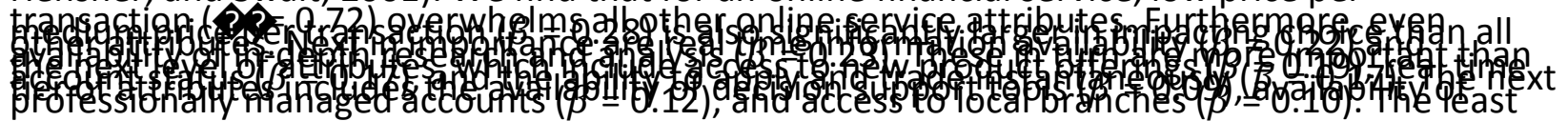


important,yet significant attribute is the availability of marketing promotions $(\{\mathrm{J}=0.04)$.

\begin{tabular}{|c|c|c|c|c|}
\hline Constructs & Variables & \begin{tabular}{|l} 
Beta- \\
Weights•
\end{tabular} & \begin{tabular}{|l|} 
Main \\
Effects. .
\end{tabular} & $\begin{array}{l}\text { Overall Feature } \\
\text { Importance•. - }\end{array}$ \\
\hline \multirow{3}{*}{$\begin{array}{l}\text { Depth of } \\
\text { Product } \\
\text { Information }\end{array}$} & $\begin{array}{l}\text { Real Time Information } \\
\text { Availability }\end{array}$ & $\begin{array}{l}0.22 ;-0.22 \\
(.008)\end{array}$ & 0.45 & $10.82 \%$ \\
\hline & $\begin{array}{l}\text { Access to New Product } \\
\text { Offerings }\end{array}$ & $\begin{array}{l}0.19 ;-0.19 \\
(.008)\end{array}$ & 0.38 & $9.33 \%$ \\
\hline & $\begin{array}{l}\text { In-depth Research and } \\
\text { Analysis }\end{array}$ & $\begin{array}{l}0.23 ;-0.23 \\
(.008)\end{array}$ & 0.46 & $11.23 \%$ \\
\hline \multirow[t]{4}{*}{ Affordability } & Price 1 (Low) & $\begin{array}{l}0.73 \\
(.014)\end{array}$ & 1.37 & $33.90 \%$ \\
\hline & Price 2 (Medium) & $\begin{array}{l}0.28 \\
(.014)\end{array}$ & NA & NA \\
\hline & Price 3 (Medium-High) & $\begin{array}{r}-0.37 \\
(.017) \\
\end{array}$ & NA & NA \\
\hline & Price 4 (High) & -0.64 & NA & NA \\
\hline \multirow[t]{3}{*}{ Ease-of-Use } & Real Time Account Status & $\begin{array}{l}0.19 ;-0.19 \\
(.008)\end{array}$ & 0.38 & $9.44 \%$ \\
\hline & Apply and Trade Instantaneously & $\begin{array}{l}0.17 ;-0.17 \\
(.008)\end{array}$ & 0.34 & $8.10 \%$ \\
\hline & Decision Support Tools & $\begin{array}{l}0.09 ;-0.09 \\
(.008)\end{array}$ & 0.18 & $4.70 \%$ \\
\hline \multirow{2}{*}{$\begin{array}{l}\text { Degree of } \\
\text { Offline } \\
\text { Capability }\end{array}$} & $\begin{array}{l}\text { Professionally Managed } \\
\text { Accounts }\end{array}$ & $\begin{array}{l}0.12 ;-0.12 \\
(.008)\end{array}$ & 0.24 & $5.84 \%$ \\
\hline & Access to LocalBranches & $\begin{array}{l}0.10 ;-0.10 \\
(.008)\end{array}$ & 0.20 & $4.75 \%$ \\
\hline \multirow[t]{4}{*}{$\begin{array}{l}\text { Marketing } \\
\text { Incentives }\end{array}$} & Marketing Promotions & $\begin{array}{l}0.04 ;-0.04 \\
(.008)\end{array}$ & 0.08 & $1.89 \%$ \\
\hline & Intercept & - & & \\
\hline & $\begin{array}{l}\text { McFadden's Rho Square = } \\
0.9644\end{array}$ & & & \\
\hline & Rho-Square Adjusted $=0.9614$ & & & \\
\hline
\end{tabular}

- All estimated beta-weights are statistically significant at $p<0.05$, standard errors in parentheses

- . Main effects arecalculated as the range of eachfeature; i.e., the highest beta-weight for that feature minus the lowest beta-weight for the feature

.. Overall importance is calculated by dividing each individual attri bute main effect by the sum of all attribute main effects

Table 3.MultinomialLogit Choice Modelfor Online FinancialServices Customers 


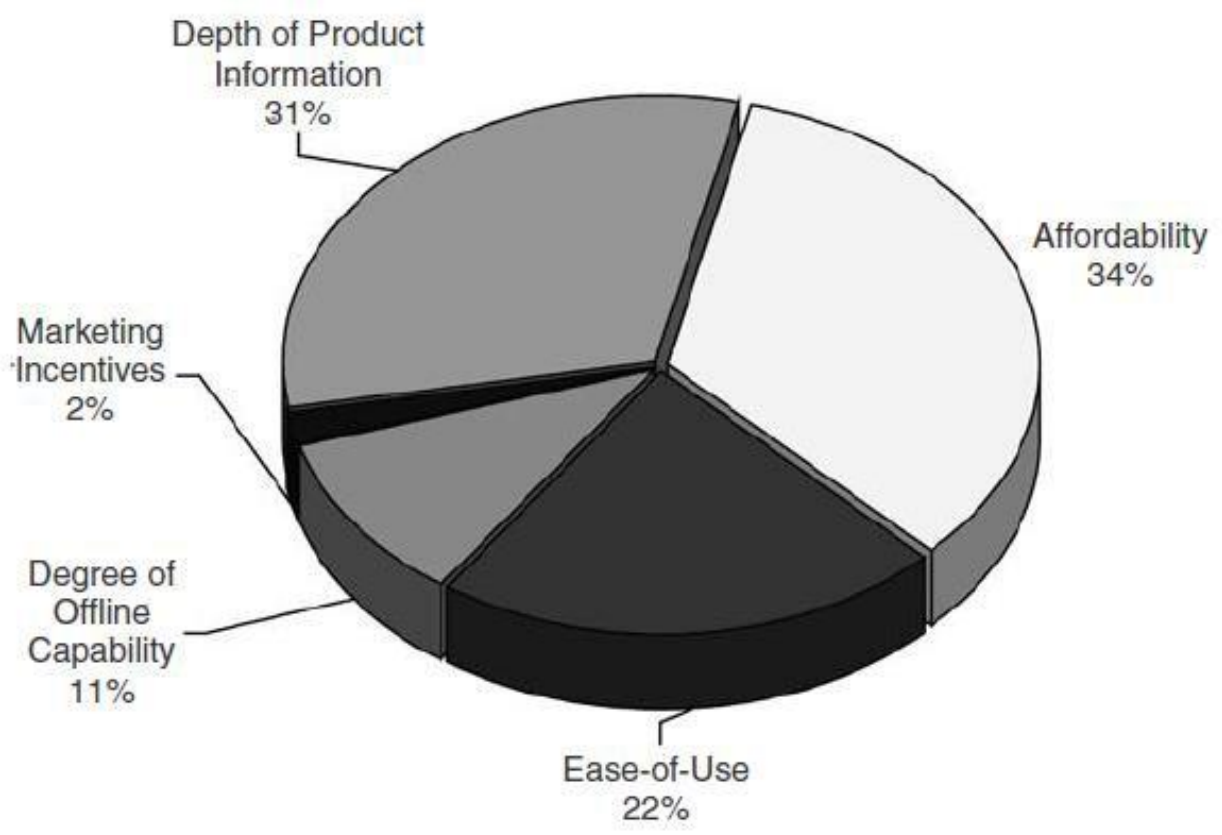

Figure 1. Relative Impact of All Factors

In keeping with our stated objective, DCA results allow us to determine the relative importance customers attach to each of the factors of an online service (Figure 1). We find that affordability of the online service is the most important factor, accounting for $33.90 \%$ of the choice of an online service. Next in importance is depth of product information, which accounts for approximately $31 \%$ of the choice of an online service. This is obtained by summing up the importance of real time information availability (10.82\%), access to new product offerings (9.33\%), and in-depth research and analysis (11.23\%). Next in importance is ease of use of the online service, which accounts for approximately $22.25 \%$ of the choice of an online service. This is obtained by summing up the importance of real time account status (9.44\%), the ability to apply and trade instantaneously (8.10\%), and the availability of decision support tools (4.70\%). Degree of offline capability accounts for approximately $10.59 \%$ of online service choice. Variables that influence online service choice include availability of professionally managed accounts (5.84\%) and access to local branches (4.75\%). Finally, marketing incentives account for the remainder, i.e., $1.89 \%$ of the choice of an online service. In the next section, we discuss the managerial and academic implications of our findings.

\section{Discussion and Conclusions}

Our study set out to determine the relative importance that customers of online services attach to factors that are commonly used by firms to compete in the online space. Overall, the results suggest that customers value a combination of depth of information, affordability, ease of use, degree of offline capability, and marketing incentives with clear tiered preferences among these factors. 
It should come as no surprise that customers of online financial services value affordability of the online service, specifically price paid per transaction. Our findings mirror numerous other studies that suggest that customers using online services are price sensitive and demand price breaks for using online services (Degeratu, Rangaswamy, and Wu, 2000; lqbal, Verma, and Baran, 2003). Our findings further suggest that the online space too is increasingly becoming competitive in that firms offering online services need to be sensitive to the affordability of their services if they wish to continue competing online. Affordability also offers the greatest leverage in getting customers to choose a particular online financial service. At the individual attribute level, low and medium prices per transaction were by far the most important attributes in driving customer choice of online services. Thus for firms competing online and needing to draw customers to their online services from other competing online services, offering an affordable service via low or medium levels of price per transaction might be the quickest way to capture customers.

For those firms who wish to avoid focusing on purely price-based competition, our results seem to offer an almost equally compelling strategic choice. By providing depth of product information, firms competing online can gain almost comparable leverage as by competing on price; $31 \%$ of customer choice versus $33.90 \%$ of customer choice respectively. In this regard, our results confirm Lynch and Ariely's (2000) findings wherein the authors found that online consumers for wine significantly valued high quality product information and in some cases exhibited decreased price sensitivity as the quality of the available information increased. By providing deep product information, firms can possibly offset a sometimes kneejerk reaction on the part of customers to choose between competing online services purely on the basis of affordability. These findings also corroborate Evans and Wurster's (1999) suggestions that customers with good quality information might tend to make decisions on attributes other than price. At the individual attribute level however, no single product information attribute is sufficient to offset low and medium levels of price per transaction. This suggests that firms wishing to avoid price competition in online financial services cannot compete by providing limited levels of product information. Firms not only have to provide in depth research and analysis, they also have to provide information about the availability of new products, as well as timely information. Product information that is dated by the standards of the online medium, though in depth, might not be adequate to compete against firms that are offering extremely affordable online services.

Firms have been encouraged to offer online services that are easy to use (Vellido, Lisboa, and Meehan, 2000; Zeithaml, Parasuraman, and Malhotra, 2000). Our results indicate that ease-of-use of online services is indeed important to customers and explains approximately $22.25 \%$ of customers' choices between competing online financial services. However, ease-of-use of the online financial service is not the most significant driver of choice and is less important than affordability and depth of product information. This suggests that the effort that firms have exerted in making online services easy to use, while necessary, is not adequate to successfully compete in an increasingly crowded online arena. At the individual 
attribute level, some attributes of online financial services such as availability of real time information and the ability to apply online and trade instantaneously are also important in driving online financial service choice. Our results indicate that perhaps customers are becoming more technologically savvy and are not willing to choose between competing online services purely on the basis of ease-of-use.

Customers do value a degree of offline capability, but at a much lower level than the above three factors. It appears that degree of offline capability is viewed as a component of online services, but not a very important one. In this regard, customers appear to require a degree of offline capability as a necessary backup in case the online capability fails to function. In such a situation, customers would like the option of having access to brick-and-mortar facilities and to trained professionals who can manage their accounts. In all other eventualities, particularly if the online service has made available detailed product information, is affordable, and easy to use, customers seem to prefer the online capability in choosing between competing online financial services. Our results validate the increasing presence of the so called "clicksand-mortar" services that enable customer transactions, interaction, and information search via the online or "clicks" portion of the service, whilst simultaneously assuring customers that the company is anchored in a more tangible environment via the "mortar" portion of the service.

Finally, the role of marketing incentives in driving customer choice between competing online services is minor at best. Online service providers need to know that customers value service functionality and value much more than any incentives that firms can provide. In the increasingly competitive online arena, it appears that depth of product information, ease of use, offline capability, and affordable price per transaction are more important than temporary incentives that firms offer.

Our results thus allow managers of online services, specifically online financial services, to understand the levers of choice when customers choose between competing online services. Furthermore, the results enable managers to quantify the impact that each of the five factors included has on driving online service choice. Managers can use our results to design online financial services that satisfy customers and because we have included specific attributes in our study, they can also understand the impact of offering specific attributes on their firms' profitability. For researchers in the nascent field of online services, our study pushes the boundaries of knowledge a little further by focusing on how to compete in the online arena with other competing providers of online services. Our study can be viewed as a template for designing similar studies in other industries besides financial services.

\section{Limitations}

Our study, while among the few to study customer choice between competing online services, has some limitations. First, it is a single industry study and hence has limited generalizability. Further research needs to be conducted that expands the scope of the findings to industries beyond the financial services industry. Examples of such research exist in the 
travel industry (Shankar, Rangaswamy, and Pusateri, 1999), the wine industry (Lynch \& Ariely, 2000), and the grocery industry (Degeratu, Rangaswamy, and Wu, 2000). Second, while our results permit us to make some generalizations, our study is essentially a cross-sectional one. We need more research that tracks the same set of customers over time. This type of longitudinal panel research of online choice behavior is enabled by using the Wharton Virtual Test Panel (see Lohse, Bellman, \& Johnson, 2000 for details). Third, our study limited the customer sample to high involvement customers. Future research needs to be conducted to see if these results are replicated among low involvement customers. However, despite the limitations, we believe that our results and conclusions add to existing scholarship on developing transaction-based online services and also enable managers to create online services that best satisfy the customers targeted.

\section{References}

Barnett, M. (2000), “Edward Jones: The Last Not-Com Brokerage.” The Standard, August 7. Ben-Akiva, M. and Lerman, S.R. (1991), Discrete Choice Analysis. Cambridge, MA: MIT Press.

Bitner, Mary Jo, Stephen W. Brown, \& Matthew L. Meuter (2000), "Technology Infusion in Service Encounters," Journal of the Academy of Marketing Science, 28 (Winter), 138149.

Danaher, P. J. (1997), "Using Conjoint Analysis to Determine the Relative Importance of Service Attributes Measured in Customer Satisfaction Surveys." Journal of Retailing, 73, 2, 235260.

Degeratu, A., Rangaswamy, A. and Wu, J. (2000), "Consumer Choice Behavior in Online and Regular Stores: The Effects of Brand Name, Price, and Other Search Attributes." International Journal of Research in Marketing, 17, 55-78.

Elrod, T., Louviere, J.J., \& Davey K.S. (1992), "An Empirical Comparison of Rating-Based and Choice-Based Conjoint Models." Journal of Marketing Research, 29, 368-377.

Evans, P. and Wurster, T.S. (1999), "Getting Real About Virtual Commerce." Harvard Business Review, November-December, 84-94.

Forman, M. (2002), “Firms Retreat From Online Brokerage.” Security Industry News, 14(27), 4-6.

Goodale, J.C., Verma, R. and Pullman, M.E. (2003), "A Market Utility-Based Model for Capacity Scheduling in Mass Services." Production and Operations Management, 12 (2), 164-185.

Green, P.E. and Srinivasan, V. (1990), “Conjoint Analysis in Marketing: New Developments with Implications for Research and Practice." Journal of Marketing, 54, 3-19.

Hensher, D.A. and Johnson, L. (1980), Applied Discrete Choice Modelling. Croom-Helm, London. 
Iqbal, Z., Verma, R. and Baran, R. (2003), "Understanding Consumer Choices and Preferences in Transaction-Based e-services." Journal of Service Research, 5, 51-65.

Joyce, E. (2002), "Paid Online Services a Tough Sell." http://cyberatlas.internet.com/big_patterns/article/0,,593_1143211,00.html.

Koufaris, M. (2002), "Applying the Technology Acceptance Model and Flow Theory to Online Consumer Behavior." Information Systems Research, 13 (2), 205-223.

Lawrence, S. (2000), “The Web’s Top Sellers.” The Industry Standard, August 7, pp. 152.

Lohse, G.L., Bellman, S. and Johnson, E.J. (2000), “Consumer Buying Behavior on the Internet: Findings from Panel Data." Journal of Interactive Marketing, 14 (1), 15-29.

Louviere, J.J. (1988), Analyzing Decision Making: Metric Conjoint Analysis. Newbury Park, CA, SAGE Publications.

Louviere, J.J.\&Woodworth, G. (1983), "Design and Analysis of Simulated Consumer Choice or Allocation Experiments: An Approach Based on Aggregate Data." Journal of Marketing Research, 20, 350-367.

Louviere, J.J. and Timmermans, H. (1990), "Stated Preference and Choice Models Applied to Recreation Research: A Review." Leisure Science, 12, 9-32.

Louviere, J.J., Hensher, D., and Swait, J. (2001), Stated Choice Methods: Analysis and Applications. Cambridge University Press.

Lynch, J. G., \& Ariely, D. (2000), "Wine online: Search cost affect competition on price, quality, and distribution." Marketing Science, 19 (1), 83-103.

McFadden, D. (1986), "The Choice Theory Approach to Market Research." Marketing Science, 5 (4), 275-297.

Pullman, M., Verma, R., \& Goodale, J., (2001), "Service design and operations strategy formulation in multicultural markets." Journal of Operations Management, 19(2), 239254.

Raman, N. and Chhajed, D. (1995), "Simultaneous determination of product attributes and prices, and production processes in product-line design." Journal of Operations Management, 12, 187-204.

Ramaswami, S., Strader, T., and Brett, K. (2001), "Determinants of Online Channel Use for Purchasing Financial Products," International Journal of Electronic Commerce, 5(2), 95 118.

Shapiro, C. and Varian, H.R. (1999), Information Rules: A Strategic Guide to the Network Economy. Boston, MA: Harvard Business School Press. 
Simmons, S. and Esser, M. (2000), "Developing Business Solutions from Conjoint Analysis," Conjoint Measurement: Methods and Applications. Anders Gustafsson, Andreas Herrmann, and Frank Huber, ed. Springer, New York, NY.

Sinha, I. (2000), "Cost Transparency: The Net's Real Threat to Prices and Brands," Harvard Business Review, 78(2), 43-48.

Shankar, Venkatesh, Arvind Rangaswamy, and Michael Pusateri (1999), "The Impact of Internet Marketing on Price Sensitivity." Working Paper, Penn State e-Business Research Center, State College, PA.

Stell, R. and Paden, N. (2002), "Creating Retail Websites for Different Consumer Shopping Orientations," Journal of Internet Commerce, 1(1), 3-16.

Swait, J. and Louviere, J.J. (1993), "The Role of the Scale Parameter in the Estimation and Comparison of Multinomial Logit Models." Journal of Marketing Research, 30, 305-314.

Timmons, H. (2000), “Online Banks Can’t Go It Alone.” Business Week, July 31, pp. 87.

Torkzadeh, G. and Dhillon, G. (2002), "Measuring Factors that influence the Success of Internet Commerce." Information Systems Research, 13 (2), 187-204.

Vellido, A., Lisboa, P.J.G. \& Meehan, K. (2000), "Quantitative characterization and prediction of on-line purchasing behaviour: A latent variable approach," International Journal of Electronic Commerce, 4(4), 83-104.

Verma, R., Iqbal, Z. and Plaschka, G. (2004), "Assessment of Customer Choices and Preferences in Online Financial Services," Working Paper, University of Utah.

Verma, R., Thompson, G.M. and Louviere, J.J. (1999), "Configuring Service Operations Based on Customer Needs and Preferences." Journal of Service Research, 1(3), 262-274.

Verma, R., Thompson, G.M., Moore, W.L. and Louviere, J.J. (2001), "Effective Design of Products/Services: An Approach Based on Integration of Marketing and Operations Management Decisions." Decision Sciences Journal, 32 (1), 165-193.

Verma, R., Plaschka, G. and Louviere, J.J. (2002), "Understanding Customer Choices: A Key to Successful Service Management." Cornell Quarterly, December.

Verma and Plaschka (2003), "The Art and Science of Customer Choice Modeling: Reflections, Advances, and Managerial Implications." Cornell Quarterly, December.

Woodruff, R.B. (1997), “Customer Value: The Next Source for Competitive Advantage." Journal of the Academy of Marketing Science, 25 (2), 139-153. 
Zeithaml, V.A., Parasuraman, A. and Malhotra, A. (2000), "A Conceptual Framework for Understanding online service Quality for Future Research and Managerial Practice." Marketing Science Institute Working Paper, Report No. 00-115. 